\title{
UTILISATION STUDY OF ORAL HYPOGLYCAEMIC MEDICINES AT A TERTIARY CARE HOSPITAL
}

\author{
Abubaker Siddiq ${ }^{1 *}$ and Bharathi DR ${ }^{1}$
}

1. Department of Pharmacology, SJM College of Pharmacy, Chitradurga-577502, Karnataka, India

Article Info: Received 11 March 2019; Accepted 3 April. 2019

Cite this article as: Siddiq A., \& Bharathi DR, (2019). UTILISATION STUDY OF ORAL HYPOGLYCAEMIC MEDICINES AT A TERTIARY CARE HOSPITAL. Journal of Biomedical and Pharmaceutical Research, 8(2).

DOI: https://doi.org/10.32553/jbpr.v8i2.585

Address for Correspondence: Abubaker Siddiq, SJM College of Pharmacy, SJM Campus, Chitradurga-577502, Karnataka, India.

Conflict of interest statement: No conflict of interest

\section{ABSTRACT:}

Drug utilization research establishes the current trend in the use of antidiabetic drugs including the new drug and to identify irrational prescription. India has a sizeable Diabetic Population with more than 72 million type-2 diabetic patients. Glycemic control remains the major goal for prevention of complications arising from diabetes. Poor glycemic control can be prevented by using rational \& safe use of anti-diabetic drugs. A prospective observational study was carried out for a period of three years with the aim to study drug utilization evaluation of Oral Hypoglycaemic Medicines. A total of 468 patients were enrolled with the inclusion criteria of patients with past history of diabetes as well as newly diagnosed cases. The study showed that diabetes is more prevalent in females than males and also found a higher prevalence of the disease among elderly patients. The study revealed the use of Metformin as the most commonly utilized drug among diabetic population. Glimeperide and Metformin were the most commonly prescribed anti-diabetic combination. The results of this study provide real-life data, which will help to formulate newer strategies to improve delivery of diabetes care.

Key words: Diabetes, Drug Utilisation, Prospective, Prevalence

\section{INTRODUCTION}

Diabetes mellitus (DM) is a metabolic disorder characterized by hyperglycaemia due to absolute or relative deficiency of insulin ${ }^{1}$. Drug utilization research establishes the current trend in the use of antidiabetic drugs including the new drug and to identify irrational prescription. India has a sizeable Diabetic
Population with more than 72 million type-2 diabetic patients. Glycemic control remains the major goal for prevention of complications arising from diabetes. Poor glycemic control can be prevented by using rational \& safe use of anti-diabetic drugs ${ }^{2}$. India is one of the epicenters of the global diabetes mellitus epidemic and has the second highest number of people with the disease in the world ${ }^{3}$. The 
incidence of Type II DM in Asian Indian people is among the highest in the world and the peak prevalence of the disease was reached $\sim 10$ years earlier in Asian Indian individuals compared with Chinese people and Japanese people ${ }^{4,5}$. Drug utilization studies are important for the optimization of drug therapy and have received a great attention in recent years. Drug utilization has been defined by the $\mathrm{WHO}$ as the marketing, distribution, prescription, and use of drugs in a society with a special emphasis on the resulting medical, social, and economic consequences ${ }^{6}$. These studies serves as a tool of investigation for epidemiological studies. The studies on antidiabetic drug utilization are important for the optimization of drug therapy ${ }^{7}$. Hence, it has been proposed to conduct this study to evaluate drug utilisation pattern of Oral Hypoglycaemic Medicines in patients admitted at tertiary care hospital.

\section{METHODOLOGY:}

A convenience sample of In-patients admitted at Basaveshwara medical college hospital was participated in this study. The 3.5 years prospective observational study was carried out from July 2014 to December 2017. This study was designed for assessment of the Prospective Patients data for evaluation of drug utilisation pattern of Oral Hypoglycaemic Medicines in patients admitted at study site. All the necessary and relevant information were collected from Case records ${ }^{2}$. Data obtained from this study were grouped and analysed by tables using SPSS software version 21.0. Categorical data was presented as frequency and percentage distribution. The study was approved by Institutional human research ethics committee of SJM college of Pharmacy.

Study design: A Prospective observational study

\section{Inclusion Criteria:}

- $\quad$ Patients of either sex who was admitted to general medicine and Paediatric wards for the treatment of Diabetes were included in the study

- With atleast one Anti-diabetic drug

- $\quad$ Admitted with co-morbidities

- Willing to give informed consent

\section{Exclusion Criteria:}

- Gestational Diabetes

- Malignancy with Diabetes

- $\quad$ Psychiatric illness with Diabetes

\section{Sources of data:}

- Patient's Case records during Hospital stay

- Medication Charts and Lab reports

\section{RESULTS:}

A total of 468 patients with diabetes mellitus were enrolled in the study, out of which 231 were males and 237 were females. Among the study population, the greatest number of patients was in the age group of 41-60 years. The duration of diabetic history was found more in patients with a history less than 5 years, the impact of higher body mass in study population was more which can be an important factor associated with the development of diabetes. The demographic characteristics of enrolled patients are presented in Table No 1. 
Abubaker Siddiq et al, Journal of Biomedical and Pharmaceutical Research

Table 1: Distribution of Demographic characteristics of diabetic patients

\begin{tabular}{|c|c|c|c|}
\hline SI. No & Category & $\begin{array}{l}\text { Number of Patients } \\
(n=468)\end{array}$ & Percentage (\%) \\
\hline \multirow[t]{3}{*}{1} & Gender & & \\
\hline & Male & 231 & $49.35 \%$ \\
\hline & Female & 237 & $50.65 \%$ \\
\hline \multirow[t]{4}{*}{2} & $\begin{array}{l}\text { Age groups } \\
\text { (Years) }\end{array}$ & & \\
\hline & $<40$ & 110 & $23.50 \%$ \\
\hline & $41-60$ & 250 & $53.40 \%$ \\
\hline & $>60$ & 108 & $23.0 \%$ \\
\hline \multirow[t]{5}{*}{3} & \multicolumn{3}{|c|}{ BMI status $\left(\mathrm{Kg} / \mathrm{m}^{2}\right)$} \\
\hline & $<18.5$ & 12 & $2.50 \%$ \\
\hline & $18.5-24.9$ & 210 & $44.8 \%$ \\
\hline & $25-30$ & 201 & $42.9 \%$ \\
\hline & $>30$ & 45 & $9.6 \%$ \\
\hline \multirow[t]{5}{*}{4} & \multicolumn{3}{|c|}{ Duration of Diabetic history (in years) } \\
\hline & $0-4$ & 200 & $42.70 \%$ \\
\hline & $5-9$ & 108 & $23.00 \%$ \\
\hline & $10-14$ & 80 & $17.00 \%$ \\
\hline & $>15$ & 80 & $17.00 \%$ \\
\hline
\end{tabular}

On the evaluation of anti-diabetic therapy in the enrolled patients, oral hypoglycaemic agents were prescribed to 183 patients as monotherapy or a combination of oral hypoglycaemic agents and 276 subjects were on insulin therapy. Managing Diabetes with insulin and oral hypoglycaemic agents was advocated for only $2 \%$ of the patients. The findings are depicted in Table No. 2.

Table 2: Distribution of Anti Diabetic Therapy

\begin{tabular}{|l|l|l|l|}
\hline SI. No & Therapy & $\begin{array}{l}\text { No. of Patients } \\
(\mathbf{n = 4 6 8 )}\end{array}$ & Percentage (\%) \\
\hline 1 & Mono therapy & 103 & 22.00 \\
\hline 2 & Dual drug therapy & 77 & 16.45 \\
\hline 3 & Triple drug therapy & 03 & 0.64 \\
\hline 4 & Insulin therapy & 276 & 58.97 \\
\hline 5 & Insulin+ mono therapy & 06 & 1.28 \\
\hline 6 & Insulin+ Dual drug therapy & 03 & 0.64 \\
\hline
\end{tabular}

Among 530 anti-diabetic drugs prescribed, 102 patients were prescribed with Sulfonylureas, out of which 94 patients were prescribed with Glimeperide, 8 patients with Glipizide, followed by Biguanides (Metformin) for 89 patients, Pioglitazone and Voglibose were considered very less for the treatment due to patients clinical Characteristics and associated Co-morbid conditions. The usage of fixed dose combinations of antidiabetes medicines encountered in the study was found more with Glimeperide and Metformin. 
Among the various anti-diabetics, Insulin was the common class of drug used accounting for $52 \%$ of the total anti-diabetics. Details of the class of anti-diabetic drugs prescribed for enrolled patients are presented in Table No 3.

Table 3: Distribution of Class of Anti-diabetics

\begin{tabular}{|l|l|l|l|}
\hline Sr. No. & Class & $\begin{array}{l}\text { No. of Patients } \\
(\mathbf{n = 5 3 0 )}\end{array}$ & Percentage \% \\
\hline 1 & Sulfonylureas & 102 & 19.24 \\
\hline 2 & Biguanides & 89 & 16.79 \\
\hline 3 & $\alpha$ - Glucosidase inhibitors & 04 & 0.75 \\
\hline 4 & Thiazolinediones & 22 & 4.15 \\
\hline 5 & Sulfonyl urea and Biguanides and & 31 & 5.84 \\
\hline 6 & $\begin{array}{l}\text { Sulfonyl urea, Biguanides } \\
\text { Thiazolidonediones }\end{array}$ & 276 & 1.13 \\
\hline 7 & Insulin & 52.00 \\
\hline
\end{tabular}

\section{DISCUSSION:}

Diabetes mellitus (DM) is a chronic disorder \& is the 7th leading cause of death worldwide. Its prevalence is continuously increasing in developed \& developing countries \& it requires a lifelong treatment. In the early stage of Diabetes the glycemic control can be achieved by lifestyle modification but in some cases it is difficult to avoid anti-diabetic drugs. However, Poor patient compliance \& clinical inertia lead to uncontrolled glycaemia. A drug utilization study is the most effective method to assess and to evaluate the prescribing attitude of a physician and helps to promote the rational use of drugs $^{2}$. The objective of the present work was to evaluate prescribing pattern of oral hypoglycaemic drugs with their clinical characteristics. In this study a total of 468 patients were enrolled with the inclusion criteria of patients with past history of diabetes as well as newly diagnosed cases. The study showed that diabetes is more prevalent in females than males. The study found higher number diabetic patients in the age group of 41-60 years indicating that the risk of Diabetes Mellitus increases after the age of 40 years, this result was similar to study of Roy $V$ et al., ${ }^{8}$. Diabetes has long been linked to obesity and being overweight. Obesity causes insulin resistance and thereby $\mathrm{DM}^{9}$. In our study, we observed more patients either obese or overweight. Boffetta et al., reported that there is a strong association between BMI and the prevalence of diabetes in Asian populations ${ }^{10}$. The present study showed that Insulin therapy was most frequently prescribed drug among monotherapy and Metformin among oral hypoglycaemic agents followed by combination of sulfonylureas and Metformin. Metformin does not promote weight gain and has beneficial effects on several cardio vascular risk factors. Accordingly, metformin is widely regarded as the first drug of choice for most patients with type-2 diabetes mellitus. The role of insulin in the management of diabetes mellitus cannot be overemphasized and people with diabetes use combinations of different types of insulin to better control and manage their condition ${ }^{11,12}$. This suggests that sulfonylureas and Metformin are the choices in the treatment of Diabetes Mellitus. There was also a higher prescribing percentage of insulin therapy, Insulin preparations help in decreasing the insulin resistance effectively hence lead to better Glycemic control. 


\section{CONCLUSION:}

Prospective observational study for drug utilization evaluation on anti-diabetic drugs was carried out on 468 patients in a tertiary care hospital. The females were higher in number in the study. Metformin was the most commonly utilized drug among diabetic population. Glimeperide and Metformin were the most commonly prescribed anti-diabetic combination. To maintain the clinical standard of prescribing, a constant effort is mandatory for every physician to follow the guidelines recommended by various International bodies.

\section{ACKNOWLEDGEMENT:}

The authors are thankful to the management of SJM vidyapeetha, Chitradurga through the Principals of SJM College of pharmacy and Basveshwara medical college \& hospital for providing necessary facilities, support and encouragement throughout the study.

\section{REFERENCES:}

1. Shanthi M. Drug utilization pattern and Pharmacoeconomic of antidiabetic drugs in patients attending a teaching hospital. Int. J Basic Clin Pharmacol 2018; 7:796801.

2. Lalit Kumar, Gupta SK, Anupam Prakash. Assessment of the prescription pattern of anti-diabetic drugs in type-2 diabetes mellitus. The Pharma innovation Journal 2018; 7(5): 392-4.

3. Ranjit Unnikrishnan et al., Diabetes mellitus and its complications in India. IJCPR 2016; 357-70.

4. Anjana, R. M. et al. Incidence of diabetes and prediabetes and predictors of progression among Asian Indians: 10-year follow-up of the Chennai Urban Rural
Epidemiology Study (CURES). Diabetes Care 2015; 38, 1441-8.

5. Chinnuswamy K, Thangamani S, Joju KS. Evaluation of Effective Insulin Preparations for Glycemic control among Type II Diabetes patients in a Tertiary Care Hospital. Journal of Medical Science and clinical Research 2018; 6(5): 632-6.

6. Tognoni G, Liberati A, Pello L, Sasanclli E, Spagnoli A. Drug utilization studies and epidemiology. Rev Epifemiol. 1983; 31: 59-71.

7. Venkateswaramurthy N, Md. Shajeem S and Sambathkumar R: Prescribing pattern of antidiabetic drugs in type-2 diabetic patients. Int. J Pharm Sci. Res 2016; 7(11): 4550-5.

8. Roy $\mathrm{V}$, Rewari S. Ambiguous drug pricing: A physician dilemma. Indian J. Pharmacol. 1998; 30:404-7.

9. Triplitt LC, Reasner CA. Diabetes mellitus. In: Dipiro JT, Talbert RL, Yee GC, Matzke G, Barbara W, Posey LM, editors. Pharmacotherapy A Pathophysiologic Approach. 8th ed. New York: The McGrawHill; 2011.

10. Boffetta $P$, McLerran $D$, Chen $Y$, Inoue $M$, Sinha R, He J, et al., Body mass index and diabetes in Asia: A cross-sectional pooled analysis of 900,000 individuals in the Asia Cohort Consortium. PLoS One 2011; 6:e19930.

11. King $\mathrm{H}$ : Insulin: availability, affordability, and harmonization. WHO Drug 1998; 4:219-23.

12. Makame $\mathrm{MH}$ and DERI Study Group: Childhood Diabetes, Insulin, and Africa. Diabet Med 1992; 9:571-3. 